\title{
Error Analysis for Interferometric SAR Measurements of Ice Sheet Flow
}

\author{
Mohr, Johan Jacob; Madsen, Søren Nørvang
}

Published in:

IEEE 1999 International Geoscience and Remote Sensing Symposium, 1999. IGARSS '99 Proceedings.

Link to article, DOI:

10.1109/IGARSS.1999.773413

Publication date:

1999

Document Version

Publisher's PDF, also known as Version of record

Link back to DTU Orbit

Citation (APA):

Mohr, J. J., \& Madsen, S. N. (1999). Error Analysis for Interferometric SAR Measurements of Ice Sheet Flow. In IEEE 1999 International Geoscience and Remote Sensing Symposium, 1999. IGARSS '99 Proceedings. (Vol. 1, pp. 98-100). IEEE. https://doi.org/10.1109/IGARSS.1999.773413

\section{General rights}

Copyright and moral rights for the publications made accessible in the public portal are retained by the authors and/or other copyright owners and it is a condition of accessing publications that users recognise and abide by the legal requirements associated with these rights.

- Users may download and print one copy of any publication from the public portal for the purpose of private study or research.

- You may not further distribute the material or use it for any profit-making activity or commercial gain

- You may freely distribute the URL identifying the publication in the public portal 


\title{
Error Analysis for Interferometric SAR Measurements of Ice Sheet Flow
}

\author{
Johan J. Mohr and Søren N. Madsen \\ Danish Center for Remote Sensing, Dept. of Electromagnetic Systems \\ Technical University of Denmark, B-348, DK-2800 Lyngby, Denmark \\ Phone: +45 4525 3800, Fax: +45 4593 1634, Email: jm@emi.dtu.dk
}

This article concerns satellite interferometric radar measurements of ice elevation and three-dimensional flow vectors. It describes sensitivity to 1) atmospheric path length changes, and other phase distortions, 2) violations of the stationary flow assumption, and 3) unknown vertical velocities and slope errors in conjunction with a surface parallel flow assumption. The most surprising result is that assuming a stationary flow the east component of the three-dimensional flow derived from ascending and descending orbit data is independent of slope errors and of the vertical flow.

\section{INTRODUCTION}

Satellite radar interferometry can be used to extract three-dimensional ice velocities and surface elevations. Direct measurements require observations from three look directions, but only two look directions are available from the ERS-1/2 configuration. This article concerns the errors in a setup, where two observations are combined with a surface parallel flow assumption, [1,2].

First phase errors are addressed. Secondly, the effect of violation of the underlying assumption of stationary flow is investigated. It is necessary to distinguish between errors in observations from the same orbit family (ascending or descending) and from different orbit families. Finally, the derivation of three velocity component from two projections is assessed, in particular the use of a surface parallel flow assumption.

\section{MODEL}

For the purpose of error analysis, the interferometric phase is linearized as

$$
\phi=-\frac{4 \pi}{\lambda}\left(B_{11}+B_{\perp} \Delta \theta-v T\right)-\frac{4 \pi}{\lambda} \Delta R+\varepsilon
$$

where $\lambda$ denotes the wavelength, $B_{\|}$the baseline parallel with the line-of-sight direction, $B_{\perp}$ the perpendicular baseline, and $\Delta \theta$ the deviation from the nominal look direction. The displacement is described by the projection of the flow vector on the line-of-sight direction, $v$, multiplied by the temporal baseline, $T$. Path length changes $\Delta R$, i.e. caused by atmospheric disturbances, are varying but with a spatial frequency much lower than the decorrelation noise $\varepsilon$. The elevation, $h$, is

$$
h=R \Delta \theta \sin \theta
$$

where $\theta$ is the look angle and $R$ the slant range.

\section{DIFFERENTIAL INTERFEROMETRY}

This section addresses errors arising when two interferograms are used for simultaneous determination of elevation and flow. The individual interferograms are assumed calibrated by using ground control points of known elevation and velocity, typically points on bedrock. An analysis relating to the use of tie-points is given in [3].

Elevation and Velocity Decomposition

By using two interferograms, (1) provides two linear equations for the unknown elevation and flow. For convenience phase is converted to path length by a multiplication with $(\lambda / 4 \pi)$, and corrected for the flat earth phase $B_{\|}$, i.e. $\phi^{\prime}=(\lambda / 4 \pi) \phi+B_{\|}$. Assuming a constant flow yields

$$
\left(\begin{array}{c}
\Delta \theta \\
v
\end{array}\right)=\frac{1}{B_{\perp, 1} T_{2}-B_{\perp, 2} T_{1}}\left(\begin{array}{cc}
-T_{2} & T_{1} \\
-B_{\perp, 2} & B_{\perp, 1}
\end{array}\right)\left(\begin{array}{l}
\phi_{1}^{\prime} \\
\phi_{2}^{\prime}
\end{array}\right)
$$

where the two interferograms are denoted 1 and 2 .

\section{Path Length Distortions}

The sensitivity of the elevation measurement to path length distortions is found by combining (2) and (3), followed by a partial differentiation. The sensitivity of the measured projected velocity $v$ to path length distortions is found likewise. For interferogram 1 the partial derivatives are

$$
\begin{aligned}
& \frac{\partial h}{\partial \phi_{1}^{\prime}}=\frac{-T_{2}}{B_{\perp, 1} T_{2}-B_{\perp, 2} T_{1}} R \sin \theta \\
& \frac{\partial v}{\partial \phi_{1}^{\prime}}=\frac{-B_{\perp, 2}}{B_{\perp, 1} T_{2}-B_{\perp, 2} T_{1}}
\end{aligned}
$$

Similar equations can be derived for interferogram 2 .

\section{Optimal Baselines}

The choice of optimal baselines is discussed in [4]. For ERS-1/2 tandem data it is found that the magnitude of the temporal and spatial baselines should be large, and that the spatial baselines should ideally be of equal magnitude, but have different signs. As long as the spatial baselines have different signs the sensitivity will at most be a factor $\sqrt{2}$ from optimal, but baselines of equal signs are less optimal.

\section{Non-Stationary Flow}

For the purpose of assessing the impact of a change in the flow, the velocity projections $v_{1}$ and $v_{2}$ corresponding to the 

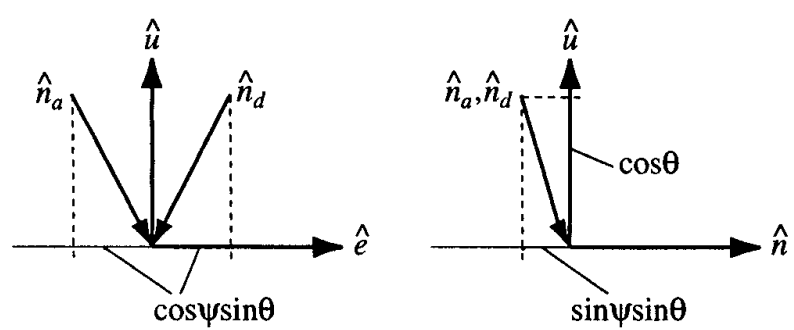

Figure 1. Ascending and descending orbit line-of-sight vectors, $\hat{n}_{a}$ and $\hat{n}_{d}$, projected on a) the $(\hat{e}, \hat{u})$-plane, and b) the $(\hat{n}, \hat{u})$-plane.

two interferograms, are written as an average value, $v_{r}$, and a difference, $v_{\varepsilon}$, thus $v_{1}=v_{\mathrm{r}}-v_{\varepsilon} / 2$ and $v_{2}=v_{r}+v_{\varepsilon} / 2$. If it, incorrectly, is assumed that $v_{\varepsilon}$ is zero, the measured velocity projection becomes

$$
v_{m}=v_{r}+\frac{1}{2} v_{\varepsilon} \frac{B_{\perp, 1} T_{2}+B_{\perp, 2} T_{1}}{B_{\perp, 1} T_{2}-B_{\perp, 2} T_{1}}
$$

In the ERS-1/2 tandem case, the choice of spatial baselines with opposite sign causes $\left|\left(\mathrm{B}_{\perp, 1}+\mathrm{B}_{\perp, 2}\right) /\left(\mathrm{B}_{\perp, 1}-\mathrm{B}_{\perp, 2}\right)\right|<1$. This implies that $v_{m}$ will be in the range $\left[v_{1} ; v_{2}\right]$. In other words, the measured velocity projection is between the velocities at the two acquisitions. For the elevation one will measure

$$
h_{m}=h_{r}+v_{\varepsilon} R \sin \theta \frac{T_{1} T_{2}}{B_{\perp, 1} T_{2}-B_{\perp, 2} T_{1}}
$$

Again, spatial baseline of opposite sign minimizes sensitivity to phase noise and static errors, for ERS-1/2 tandem data.

\section{VECTOR FLOW ESTIMATION}

This section concerns the estimation of 3-dimensional vector velocities $\vec{v}=\left(v_{e}, v_{n}, v_{u}\right)$, by combining measurements from ascending and descending orbits.

Flow from Ascending and Descending Orbit Measurements

The ascending and descending orbit ground tracks are assumed having a direction of $-\psi$ and $180+\psi$ respectively. With an angle of incidence, $\theta$, the projections of the line-ofsight vectors $\hat{n}_{a}$ and $\hat{n}_{d}$, on the unit vectors in a Cartesian east, north, and up system, become

$$
\begin{aligned}
& \hat{n}_{a} \cdot \hat{e}=-\hat{n}_{d} \cdot \hat{e}=\cos \psi \sin \theta \\
& \hat{n}_{a} \cdot \hat{n}=\hat{n}_{d} \cdot \hat{n}=\sin \psi \sin \theta \\
& \hat{n}_{a} \cdot \hat{u}=\hat{n}_{d} \cdot \hat{u}=-\cos \theta \\
& \text { Now } v_{a}=\hat{n}_{a} \cdot \vec{v} \text { and } v_{d}=\hat{n}_{d} \cdot \vec{v} \text {, i.e. } \\
& v_{a}=v_{e} \cos \psi \sin \theta+\left(v_{n} \sin \psi \sin \theta-v_{u} \cos \theta\right) \\
& v_{d}=-v_{e} \cos \psi \sin \theta+\left(v_{n} \sin \psi \sin \theta-v_{u} \cos \theta\right)
\end{aligned}
$$

It is seen, that the east velocity, $v_{e}$, can be found unambigu- ously from the difference of the ascending and descending orbit velocity projections as

$$
v_{e}=\frac{1}{2 \cos \psi \sin \theta}\left(v_{a}-v_{d}\right)
$$

However, the north velocity, $v_{n}$, and the up velocity, $v_{u}$, components in (9) cannot be separated. What can be found is

$$
v_{n} \sin \psi \sin \theta-v_{u} \cos \theta=\frac{1}{2}\left(v_{a}+v_{d}\right)
$$

Here the surface parallel flow assumption, or another constraint, is required to separate the north and up components. Assuming a flow parallel to a level surface yields

$$
v_{n}=\frac{1}{2 \sin \psi \sin \theta}\left(v_{a}+v_{d}\right)
$$

Equation (10)-(12), and the ambiguities, are illustrated in Fig. 1a-1b. Here it is also noted that the ratio between N-S and $\mathrm{E}-\mathrm{W}$ errors is tan $\psi$.

\section{Unknown Vertical Velocity Component}

If $v_{u}$ is different from zero, but not accounted for, the difference between the derived velocity $\vec{v}_{m}$ and the correct velocity $\bar{v}_{r}$ is, using (9), (10), and (12), found to be

$$
\vec{v}_{m}-\vec{v}_{r}=-v_{u}\left(\begin{array}{c}
0 \\
\cot \theta / \sin \psi \\
1
\end{array}\right)
$$

\section{Slope Errors}

The slope is needed when a surface parallel flow assumption are applied, and used to separate the north and up components. Thus, (13) can be used for slope errors also. Here slope is defined as $\partial h / \partial e$ and $\partial h \partial n$, and small slope errors denoted $\Delta \alpha_{e}$ and $\Delta \alpha_{n}$. For a nominally level surface, a surface normal error, $\Delta \hat{n}_{s}=\left(-\Delta \alpha_{e},-\Delta \alpha_{n}, 0\right)$, gives an up component error of $\Delta \hat{n}_{s} \cdot \vec{v}$, which can be substituted for $v_{u}$ in (13).

\section{Non-Stationary Flow}

Now consider the effect of a change in the flow velocity between the measurements from different look directions. The flow vectors corresponding to each look direction are written using the average velocity $\bar{v}_{r}$ and a difference $\bar{v}_{\varepsilon}$, i.e. $\vec{v}_{d}=\vec{v}_{r}-\vec{v}_{\varepsilon} / 2$ and $\vec{v}_{a}=\vec{v}_{r}+\vec{v}_{\varepsilon} / 2$. Assuming a level flow, the error velocity $\vec{v}_{\varepsilon}$ is written as $\left(\left|\vec{v}_{\varepsilon}\right| \sin \gamma,\left|\vec{v}_{\varepsilon}\right| \cos \gamma, 0\right)$, where $\gamma$ is the direction of the change. Combining (9), (10), and (12) yields

$$
\vec{v}_{m}-\vec{v}_{r}=\frac{1}{2}\left|\vec{v}_{\varepsilon}\right|\left(\begin{array}{c}
\tan \psi \cos \gamma \\
\cot \psi \sin \gamma \\
0
\end{array}\right)
$$

for the difference between the derived velocity $\vec{v}_{m}$ and the average value $\vec{v}_{r}$. 
Table 1. Baselines and acquisition geometry for example data. See also [1].

\begin{tabular}{cr}
\hline \multicolumn{2}{c}{ Storstrømmen Example } \\
\hline Parameter & Value \\
\hline$B_{\perp, 1, a}$ & $-139 \mathrm{~m}$ \\
$B_{\perp, 2, a}$ & $20 \mathrm{~m}$ \\
$B_{\perp, 1, d}$ & $-19 \mathrm{~m}$ \\
$B_{\perp, 2, d}$ & $1 \mathrm{~m}$ \\
$T$ & $1 \mathrm{day}$ \\
$R$ & $860 \mathrm{~km}$ \\
$\theta$ & $23 \mathrm{deg}$ \\
$\psi$ & $28 \mathrm{deg}$ \\
\hline
\end{tabular}

For glaciers with a seasonally varying velocity, the direction of flow is often constant, and only the magnitude changes. From (14) it is seen, that even in such a case, the measured flow will not necessarily be aligned with the flow.

It is also noted that the ratio of the flow measurement error and the flow change $\left|\vec{v}_{\varepsilon}\right| / 2$ is between $\tan \psi$ and $1 / \tan \psi$.

\section{STORSTRØMMEN EXAMPLE}

The described error equations are applied to the ERS-1/2 tandem data set from the Storstrømmen Glacier, Northeast Greenland, described in table 1 , see also [1].

Impact of Atmospheric Disturbances

A typical path length error of $0.5 \mathrm{~cm}$ is used as an example, and the results summarized in table 2 . The effect on the decomposed velocities and elevations for each track is calculated from (4) and (5). The resulting effect on the east and north components is found by using (10) and (12).

Impact of an Unknown Vertical Velocity and Slope errors

From (13) it is found that a vertical velocity of $1 \mathrm{~m} / \mathrm{y}$ corresponds to a northward flow component of $5 \mathrm{~m} / \mathrm{y}$. Likewise, a slope error of $1^{\circ}$ in the direction of the flow corresponds to 9\% error on the north component of the flow.

\section{Impact Non-Stationary Flow}

A $1 \mathrm{~m} / \mathrm{y}$ change in the horizontal flow, gives at most a $0.4 \mathrm{~m} / \mathrm{y}$ change in the line-of-sight velocity. It is a matter of definition whether the measured velocity projection should be considered erroneous. The opposite signs of the spatial baselines implies that the measured velocity is a value between
Table 2. The effect of path length errors for the Storstrømmen example in table 1 .

\begin{tabular}{crrrrrrr}
\hline \multicolumn{6}{c}{ Impact of a $0.5 \mathrm{~cm}$ path length change } \\
\hline Pair & \multicolumn{1}{c}{$\Delta h_{a}$} & \multicolumn{1}{c}{$\Delta h_{d}$} & \multicolumn{1}{c}{$v_{a}$} & $v_{d}$ & $\Delta v_{e}$ & $\Delta v_{n}$ \\
& {$[\mathrm{~m}]$} & {$[\mathrm{m}]$} & {$[\mathrm{m} / \mathrm{y}]$} & {$[\mathrm{m} / \mathrm{y}]$} & {$[\mathrm{m} / \mathrm{y}]$} & {$[\mathrm{m} / \mathrm{y}]$} \\
\hline asc, 1 & -10.6 & 0 & 0.23 & 0 & 0.33 & 0.62 \\
asc, 2 & 10.6 & 0 & 1.60 & 0 & 2.33 & 4.36 \\
desc, 1 & 0 & -84.0 & 0 & 0.09 & -0.13 & 0.26 \\
desc, 2 & 0 & 84.0 & 0 & 1.73 & -2.50 & 4.71 \\
\hline
\end{tabular}

those at the two acquisitions, see (6). By using (7) a $1 \mathrm{~m} / \mathrm{y}$ change is found to cause a $-2.3 \mathrm{~m}$ and $-18.0 \mathrm{~m}$ elevation change for the ascending and descending measurements respectively. For many flow directions it would be less.

Secondly, (14) shows that a $1 \mathrm{~m} / \mathrm{y}$ change in flow between ascending and descending orbit acquisitions, will at most result in a $0.9 \mathrm{~m} / \mathrm{y}$ deviation from the average value.

\section{CONCLUSIONS}

Equations have been derived for the effect of phase errors, and imperfections in the stationary flow assumption as well as a surface parallel flow assumption. It is found that

- The east component can be found unambiguously from ascending and descending orbit data. An additional constraint are needed to separate the north and up components

- Spatial baselines of opposite sign are favorable.

- For high latitudes, the derivation is well behaving.

\section{REFERENCES}

[1] J.J. Mohr, N. Reeh, and S.N. Madsen, "Three Dimensional Glacial Flow and Surface Elevation Measured with Radar Interferometry," Nature, vol. 391, pp. 273-276, 1998.

[2] I. Joughin, R. Kwok, and M. Fahnestock, "Interferometric Estimation of Three-Dimensional Ice-Flow Using Ascending and Descending Passes," IEEE Trans. Geosci. Rem. Sens. vol. 36, pp. 25-37, January 1998.

[3] I. Joughin, R. Kwok, and M. Fahnestock, "Estimation of ice-sheet motion using satellite radar interferometry: method and error analysis with application to Humboldt Glacier, Greenland," J. Glac, vol. 42, pp. 564-575, 1996.

[4] J.J. Mohr, and S.N. Madsen, "Application of interferometry to studies of glacier dynamics," IGARSS'96, Lincoln, Nebraska, USA, 27-31 May 1996, pp. 972-974. 